\title{
Reciprocal Development of Parent-adolescent Support and Adolescent Problem Behaviors
}

\author{
Susan J. T. Branje, William W. Hale III and Wim H. J. Meeus \\ Utrecht University, Netherlands
}

\section{INTRODUCTION}

Human development takes place in the context of relationships with others. These relationships are thought to influence individuals' behavior and developmental course (Reis, Collins, \& Berscheid, 2000). Parent-child relationships are among the most important and central of human relationships, especially during the period of childhood and adolescence. Parents are an important source of support, although the relative impact of parental support may change over the life course. Perceived parental support concerns the perception of parents as available for support when needed. In the current chapter we will examine how parental support is related to adolescent adjustment over time.

\section{ASSOCIATIONS BETWEEN PARENTAL SUPPORT AND ADOLESCENT ADJUSTMENT}

Social support from parents is thought to be a major protective factor for adolescents (Wills \& Resko, 2004). Adolescents who perceive higher levels of support generally have less problems and higher wellbeing than adolescents with lower levels of parental support. Lower levels of parental support tend to be concurrently related with higher levels of a variety of adjustment problems, including delinquent activities (Windle, 1992), violent behavior (Zimmerman, Steinman, \& Rowe, 1998), antisocial behavior (Barnes \& Farrell,

What Can Parents Do?: New Insights into the Role of Parents in Adolescent Problem Behavior

Edited by M. Kerr, H. Stattin and R. C. M. E. Engels @ 2008 John Wiley \& Sons, Ltd. ISBN: 978-0-470-72363-0 
1992; Deković, Janssens, \& Van As, 2003; Vazsonyi, 2004), aggression (Lopez et al., 2006), alcohol and substance use (Maton \& Zimmerman, 1992; Windle, 1992), depressive symptoms (McCarty et al., 2006; Mounts, 2004; Windle, 1992), loneliness (Mounts, 2004) and lower levels of self-esteem (Parker \& Benson, 2005).

In our own work we have also documented concurrent associations between parental support and adolescent adjustment. In particular, Helsen, Vollebergh \& Meeus (2000) examined associations between parental support and emotional problems over the course of adolescence. They used data from the first wave of the six-year three-wave Dutch longitudinal project "Utrecht Study of Adolescent Development (USAD) 1991-1997" (Meeus \& 't Hart, 1993), consisting of 2589 Dutch adolescents (1193 boys) in four age categories: early adolescence (between 12 and 14, n=549), middle adolescence (between 15 and $17, n=798$ ), late adolescence (between 18 and 20, $n=645$ ), and post adolescence (between 21 and 24, $n=597$ ). The perceived level of parental support was measured by the role-relation method (Fisher, 1982; Meeus, 1989). The question asked was "when you are having problems in relations with someone else, or when you are feeling lonely, who helps you? Please note that this question refers to problems in relations with others, for example when you are quarrelling, when someone does not like you or when you are feeling lonely." The adolescents were asked to indicate on a 10-point scale the degree of support they received from father, mother, and friends when such problems arise. Parental support consisted of average scores of support from fathers and mothers. Emotional problems were measured by a composite of self-report measures: scales for psychological stress and depression, the feeling of general wellbeing and happiness, general physical health and complaints in bodily functioning, and the tendency to have suicidal thoughts. An exploratory factor analysis revealed a single-factor solution with loadings of 0.60 and higher, which explained $54.1 \%$ of the variance. Each adolescent was assigned a factor score, derived by using the short regression method, for the construct Emotional Problems.

Results of this study revealed a significant moderate correlation of parental support with emotional problems $(r=0.25)$. Multiple regression analyses of emotional problems on the support of parents and friends, age, and sex revealed that parental support interacted with all the other variables. Parental support was found to be stronger related to emotional problems for girls $(\beta=-0.32)$ than for boys $(\beta=-0.16)$. The effect of parental support also decreased during adolescence: parental support was stronger related to emotional problems for younger adolescents than for older adolescents. Adolescents of all ages who perceived low levels of support reported a high level of emotional problems. In particular younger adolescents with high levels of parental support reported lower levels of emotional problems. The interaction effect between parental support and the support of friends indicated that parental support is negatively related with emotional problems for all adolescents, but this effect is stronger among adolescents who perceive strong 
support from friends compared with those who perceive little support from friends. Among adolescents with higher parental support, peer support was associated with lower levels of depression, whereas among adolescents with lower parental support, peer support was associated with higher levels of depression. The latter finding might indicate a tendency to "turn to friends" in times of distress when parents are not available.

A study of the extent to which siblings affect each other's development and psychosocial adjustment during adolescence (Branje et al., 2004) also included effects of parental support. The participants in this study were 285 Dutch middle-class two-parent families with at least two siblings between 11 and 15 years of age (older child $\mathrm{M}$ age $=14$ years, younger child $\mathrm{M}$ age $=12$ years), who participated in the Nijmegen Family and Personality Project (Haselager \& Van Aken, 1999), a three-wave longitudinal study with one-year intervals between subsequent waves. Perceived parental support was measured with the Relational Support Inventory (RSI) (Scholte, Van Lieshout, \& Van Aken, 2001). This inventory involves 24 questions representing four dimensions of perceived support measured by six items each along a five-point Likert-scale ranging from very untrue of this person (1) through sometimes untrue, sometimes true of this person (3) to very true of this person (5). The first support dimension, perceived Quality of Information, assesses the quality of information and withholding of information. A sample item is: "This person explains or shows how I can make or do something." The second support dimension is perceived Respect for Autonomy and assesses respect for autonomy and limit setting. For example, "This person lets me solve problems as much as possible on my own but also provides help when I ask for it." The third support dimension is perceived Emotional Support and assesses warmth as opposed to hostility. A sample item is: "In this person's view, I can't do anything right: he/she is always criticizing me." The fourth support dimension is perceived Convergence of Goals and assesses the perceived level of convergence as opposed to divergence of goals. For example: "This person and I have many conflicts with regard to my school achievement, future, or career opportunities" (reverse scoring). Adolescents judged the support they perceived from each other and from their father, mother, and best friend. The RSI total scores were averaged across all 24 items. Cronbach's alphas ranged between 0.80 and 0.87 . To assess internalizing and externalizing behavior in a non-clinical setting, the Nijmegen Problem Behavior List (NPBL) (Scholte, Vermulste \& De Bruyen, 2001) was used. Items are formulated to represent problem behavior. The NPBL contains 16 items on a five-point scale and is validated as both a self-report measure and as an other-report measure. Internalizing and externalizing problem behavior of adolescents was assessed by self-ratings of the adolescents and by ratings of fathers and mothers. Ratings of fathers and mothers were averaged. Internalizing behavior is measured with nine items measuring withdrawn and anxious/depressed behavior (e.g., "I withdraw from others, I feel sad, unhappy"). Cronbach's alpha varies from 0.81 to 0.88 for the different versions. Externalizing behavior is measured with seven 
items measuring aggressive and delinquent behavior (e.g., "I readily threaten others with violence," "I cheat others"). Cronbach's alpha varies between 0.77 and 0.89 .

Perceived parental support was found to correlate significantly with both self-reported and parent-reported internalizing and externalizing behavior, except for younger siblings' parent-reported internalizing behavior (see Table 6.1).

Table 6.1 Correlations between parental support and internalizing and externalizing problem behavior

\begin{tabular}{lll}
\hline & $\begin{array}{l}\text { Perceived } \\
\text { paternal support }\end{array}$ & $\begin{array}{l}\text { Perceived } \\
\text { maternal support }\end{array}$ \\
\hline Internalizing behavior & & $-0.29^{* *}$ \\
Younger sibling, self-report & $-0.29^{* *}$ & -0.06 \\
Younger sibling, parent-report & -0.08 & $-0.31^{* *}$ \\
Older sibling, self-report & $-0.36^{* *}$ & $-0.17^{* *}$ \\
Older sibling, parent-report & $-0.20^{* *}$ & $-0.41^{* *}$ \\
Externalizing behavior & & $-0.21^{* *}$ \\
Younger sibling, self-report & $-0.40^{* *}$ & $-0.52^{* *}$ \\
Younger sibling, parent-report & $-0.24^{* *}$ & $-0.30^{* *}$ \\
Older sibling, self-report & $-0.51^{* *}$ & \\
Older sibling, parent-report & $-0.34^{* *}$ & \\
${ }^{* *} p<0.01$ & &
\end{tabular}

A series of multiple regression analyses in which internalizing and externalizing behavior were regressed on several background variables, support from father, mother, best friend, and sibling, and sibling problem behavior, revealed that father support was still significantly related to older adolescents' self-reported $(\beta=-0.31)$ and parent-reported $(\beta=-0.34)$ externalizing behavior and older adolescents' self-reported internalizing behavior $(\beta=-0.33)$, with older adolescents who perceived more support from father revealing less problems. Longitudinal effects of parental support on externalizing or internalizing behavior were also examined, thereby controlling for stability of problem behavior. Results showed that paternal and maternal support did not predict changes in adolescent problem behavior one year later.

In sum, many studies have provided evidence for concurrent associations between parental support and adolescent internalizing and externalizing problem behavior. Although most of these studies assumed that higher levels of parental support lead to better psychosocial adjustment, the opposite direction of effects is equally possible, with adolescent problem behavior leading to changes in parental support. Other possibilities are that parental support and adolescent problem behavior reciprocally affect each other, or that third variables cause their relation. Longitudinal studies that focused on the direction of effects between parental support and adolescent problem 
behavior while controlling for stability and initial associations between problem behavior and support are sparse, however. In the remainder of this chapter we will discuss different theoretical perspectives regarding the underlying processes of the associations between parental support and adolescent problem behavior, as well as longitudinal evidence for these perspectives.

\section{THEORETICAL FRAMEWORKS FOR THE LINKS BETWEEN PARENTAL SUPPORT AND ADOLESCENTS' ADJUSTMENT}

Several theoretical perspectives offer explanations for the links between parental support and adolescent adjustment problems. Most of these perspectives focus on effects of parental support on adolescent problem behaviors. These socialization theories have been summarized by Hartup (1978) under the label of social mold model. According to these theories, parental socialization efforts literally mold a child's behavior, and a lack of parental support leads to adolescent problem behavior. Other perspectives emphasize effects of adolescent problem behavior on parental support or bidirectional effects between parental support and adolescent problem behavior.

\section{Effects of Parental Support on Adolescent Problem Behavior}

\section{Stress-buffering Model}

According to the stress-buffering model (Cohen \& Wills, 1985; Windle, 1992), parental support can protect against adolescent problem behavior by neutralizing the adverse effects of a risk factor such as stressful life events. Similarly, a vulnerability-buffering model suggests that parental support might reduce the effects of a personal characteristic such as negative affect on problem behavior (Cohen \& Wills, 1985). In contrast to a direct effects model, the stress-buffering model suggests that parental support is only protective under conditions of stress and moderates the negative consequences of high levels of stress. The perception of being accepted and valued is thought to boost self-esteem, confidence, and efficacy (Pierce et al., 2000) and makes it easier to cope effectively with stressful life events. Feeling supported and loved by one or both parents is thought to ameliorate the effects of stress on depression (Wills \& Cleary, 1996). Similarly, supportive relationships with parents are thought to be related to adaptive coping that promotes prosocial behavior, whereas unsupportive relationships with parents are thought to be related to patterns of maladaptive coping that might lead to externalizing behavior problems (Wills \& Resko, 2004).

There is not much empirical evidence for the stress-buffering hypothesis. Cross-sectional studies offer mixed support and there are only a few studies that have addressed the stress-buffering hypothesis using longitudinal designs. 
Burton, Stice \& Seeley (2004) did not find any support for parental support buffering the effects of negative life events on depression in a longitudinal study among adolescent girls aged 11 to 15 years. DuBois et al. (1992) tested the stress-buffering hypothesis in a sample including 61\% African-American and $39 \%$ White adolescents. They found no moderating effect for parental support on the relations of major life events and daily hassles with psychological adjustment and academic performance over a two-year period. Windle (1992) examined the stress-buffering effects of parent and friend support on alcohol consumption, alcohol problems, delinquent activity, and depressive symptoms among White, predominantly middle-class, adolescent males and females. He found no support for the buffering hypothesis of parental support among both males and females. Also, longitudinally, no support for the stressbuffering hypothesis was found for alcohol and marijuana use (Zimmerman et al., 2000). Similarly, no support was found for the vulnerability-buffering model regarding the onset of substance abuse (Measelle, Stice, \& Springer, 2006). The increased risk of substance abuse onset due to negative emotionality or depressive symptoms did not decrease as a function of higher levels of perceived parental support.

Some support for the stress-buffering hypothesis was found in a study by Ge et al. (1994), who used latent growth curve models in a four-year longitudinal study to examine the moderating effect of maternal support on the link between depression and stressful life events. Their findings showed that the level of depressive symptoms is related to the level of life events for both boys and girls and that maternal support buffers these effects of stress on depressive symptoms of adolescents. However, only for girls with less supportive mothers, change in depressive symptoms is significantly related to change in stressful events.

In sum, longitudinal studies provide only limited support for the stressbuffering hypothesis. Perhaps stressful life events have an immediate effect on adolescents but have only minimal lasting consequences (Zimmerman et al., 2000), which might explain why the buffering role that parental support has been found to play in cross-sectional studies is often not found in longitudinal designs.

Three other models regarding relations between parental support and adolescent problem behavior can be distinguished, that is, a direct effects model, a child-effects model, and a reciprocal effects model. These models will be discussed below. As studies that examined these models often addressed two or more of these models at the same time, we will present empirical evidence for each of the models after describing the three models.

\section{Direct effects model}

A direct effects model assumes that parental support has a generalized positive effect on adolescents. Deficits in parental support might have a main effect 
on adolescent problem behavior and directly increase the risk for problem behaviors (Baumrind, 1991; Windle, 1992). Hirschi's Social Control Theory (Hirschi, 1969) is an example of a perspective in the social mold tradition that assumes direct effects of parental support on externalizing behavior: Adolescents who have stronger ties to parents would have higher self-control and restrain from delinquent behavior. Deficits in parental support might lead to a weaker bond and identification with parents and subsequently to more delinquent behavior. Adolescents who experience deficits in parental support are thought to identify with their parents to a lesser extent, which in turn interferes with the internalization of parental norms and leads to deviant behavior or substance abuse. Internalizing problems can also be affected by direct effects of parental support. The perception of being accepted and valued boosts self-esteem and self-efficacy, which protects against depressive feelings (Windle, 1992).

\section{Effects of Adolescent Problem Behavior on Parental Support Child Effects Model}

The direction of effects between parental support and adolescent problem behavior could also go from child to parent. Child characteristics are thought to be important in shaping parenting (Belsky, 1984; Patterson, 1982). Bell (1968) was among the first to emphasize child effects in socialization processes, and proposed a child-effects model, which suggests that children and adolescents basically mold parents' behaviors in an attempt to adjust to their children's behaviors (Bell \& Chapman, 1986). This perspective suggests that parents react to the actions of their children (Kerr \& Stattin, 2003). According to this perspective, adolescent behavior would elicit more or less parental support.

In respect to depression, Coyne (e.g., Coyne, Burchill, \& Stiles, 1991) has proposed depression as a gradual escalation of depressed persons initially eliciting supportive behaviors from significant others (such as parents or partners) by means of their display of depressive behaviors (e.g., Hale, 2001). The depressed person specifically looks for support from others to offset their negative cognitive beliefs that others are rejecting them (e.g., Beck et al., 1979).

These interpersonal interactions between the depressed person and the other are believe to induce a negative mood in the other person. Hence, over time, this initial supportive interaction becomes increasingly rejecting and a process of support erosion emerges in which people are likely to stop supporting depressed individuals as a consequence of their negative self-statements, complaints, apathy, reassurance seeking, and social inadequacy (Coyne, 1976). This rejection confirms depressed individuals' negative beliefs that they were 
being rejected by others all along (e.g., Hollon \& Beck, 1994). This interpersonal theory of depression has received support in both (young-)adult (e.g., Segrin \& Dillard, 1992) and adolescent studies (e.g., Joiner, 1999). Additionally, a recent longitudinal study by Hale et al. (in press) of young adolescents and perceived parental rejection also lends credence to this theory.

For externalizing behavior, similar patterns have been described. Adolescents' behavior could elicit aversive reactions and a decrease in support of parents (Patterson, 1982). Also, parents might emotionally reject their adolescent with externalizing problem behavior (Baumrind \& Moselle, 1985) and become less supportive. Parents might also become increasingly tolerant to the behavior of their child, however (Bell \& Chapman, 1986), and remain supportive. Moreover, parents might try to get their adolescent with externalizing problem behavior back on a nondeviant track by increasing their level of support, although at the present time we are not aware of any empirical evidence of this.

\section{Reciprocal Effects Between Parental Support and Adolescent Problem Behavior}

Different theories emphasize bidirectionality of effects, in which relationship partners influence each other and contribute to individual developmental outcomes (Bell, 1968; Bell \& Chapman, 1986; Lollis \& Kuczynski, 1997; Sameroff, 1983). In recent decades, the transactional character of relations between individual characteristics and family relationships has been emphasized: family members develop in a continuous process of transactions, in which individual characteristics and relationship characteristics influence each other reciprocally (Lollis \& Kuczynski, 1997; Maccoby, 1984; Sameroff, 1983). Thus, it is likely that parental support and adolescent problem behavior mutually affect each other, with adolescent problem behavior eliciting changes in support and parental support influencing adolescent behavior.

Although many studies have investigated associations between adolescent behavior and parental support, most of these studies used concurrent or cross-lagged correlations that do not permit conclusions about the underlying processes (Neyer \& Asendorpf, 2001). To examine transactions between parental support and adolescent behavior, longitudinal causal models are needed, such as path analyses with cross-lagged effects or growth-curve models, which control for concurrent relations at time 1, stability, and correlated change of adolescent behavior and parental support when estimating the reciprocal effects between these variables. Only this type of analysis can disentangle the extent to which differences in parental support predict changes in adolescent problem behavior over time and vice versa. It should be noted, however, that this analysis does not provide conclusive evidence for causal direction of effects because alternative explanations, such as third variables, may still play a role. 


\section{Evidence for Direct Effects, Child Effects, and Reciprocal Effects}

Longitudinal studies examining direct or reciprocal effects between parental support and problem behavior while controlling for initial associations and stability of problem behavior are relatively sparse. Most of these studies only tested direct effects of parental support instead of reciprocal effects between support and problem behavior. In a study among adolescent girls aged 11 to 15 years, no effects of parental support on changes in depression were found (Burton, Stice, \& Seeley, 2004). Also, deficits in parental support predicted future increases in alcohol use among adolescents aged 12-17 (Stice, Barrera Jr., \& Chassin, 1998). Similarly, in a five-year longitudinal study of adolescent girls using hazard models, deficits in parental support were found to predict future substance abuse onset (Measelle, Stice, \& Springer, 2006). Moreover, using a pretest-posttest design, Yang \& Yeh (2006) found that enacted parental support predicted changes in anxiety among Taiwanese adolescents who went through the final school examinations but this effect was moderated by intimacy with parents. Anxiety was reduced when adolescents perceived high relationship intimacy with parents, and increased when there was low relationship intimacy.

Gender differences in the effects of parental support have also been found. For example, among middle adolescents, higher parental support was found to predict decreases in alcohol problems, delinquent activity and depressive symptoms for girls but not for boys (Windle, 1992). Meadows, Brown, \& Elder (2006) investigated gender differences in the associations among stressful life events, parental support, and depression during late adolescence and emerging adulthood. Their results showed that both maternal and paternal support reduce depressive symptoms during late adolescence but not during emerging adulthood. Maternal support and depressive symptoms were more strongly related for females than for males, but no gender difference was found for support from fathers. Also, whereas maternal support seemed to be more effective for females than paternal support, for males no differences between the relation of support from mothers and fathers with depressive symptoms was found.

Some studies examining reciprocal effects between parental support and adolescent problem behavior found further evidence for direct effects of parental support. For instance, in a sample of male African-American adolescents, Zimmerman et al. (2000) found that parental support predicted a decrease in anxiety and depression six months later, but not in alcohol and marijuana use or for delinquency. However, anxiety and depression did not predict parental support over time, indicating that adolescents' problems do not elicit increased levels of parental support longitudinally. Additionally, Sheeber et al. (1997) found that family support at time 1 significantly predicted depression one year later for 14 to 20 year olds: adolescents who received less family support had more depressive symptoms one year later. Time 1 depression did not significantly predict time 2 family support. Furthermore, 
Stice, Ragan, \& Randall (2004) tested bidirectional effects between perceived parental support and depression using longitudinal data from adolescent girls. Deficits in parental support predicted future increases in depressive symptoms as well as onset of major depression. In contrast, initial depressive symptoms and major depression did not predict future decreases in parental support. These results are consistent with the direct effect model of parental support. Rather than depression leading to support erosion, these findings suggest that low parental support has a direct effect on depressive symptoms over time.

In a community sample, regression analyses revealed that parental support was not independently related to adolescents' depression two years later when controlling for time 1 depression (Young et al., 2005). Also, time 1 depression did not predict changes in parental support over time. However, the authors did find that the interaction between parental support and peer support significantly predicted depression, which was interpreted as parental support moderating the relationship between peer support and depression. Anticipated peer support was found to lead to less depression among adolescents with high parental support, and to higher levels of depression for adolescents with low parental support. Nevertheless, these results could also be interpreted as peer support moderating the effect of parental support. If this is the case then this would indicate that when relationships with peers are supportive, higher parental support leads to less depression, but when relationships with peers are nonsupportive, higher parental support leads to more depression. Among adolescents with low anticipated peer support, higher parent support did not buffer for depressive symptoms. Thus, these data suggest a direct effects model of parental support, whereby the direction of the effect is moderated by supportiveness of peers.

Thus, evidence for the direct effect model of parental support to adolescent problems is mixed. Results are much more consistent regarding effects of parental support on internalizing problems than regarding effects of parental support on externalizing problems. Furthermore, effects of internalizing problems on parental support were mostly found to be non-significant. Although many of the studies did not test reciprocal effects and can therefore not rule out possible effects of problem behavior on support, the studies that tested reciprocal effects mostly did not find effects of problem behavior on support. Only one study found evidence for support erosion in relation to depression (Slavin \& Rainer, 1990). Depressive symptoms were found to predict a decrease in perceived family support for girls but not boys during late adolescence.

Some evidence for support erosion in response to externalizing behavior has been reported in studies examining reciprocal effects, however. Using the same dataset as Measelle, Stice, \& Springer (2006), Huh et al. (2006) tested the hypothesis that perceived parenting would show reciprocal relations with adolescents' problem behavior. They found that higher externalizing behavior and substance abuse predicted future decreases in perceived parental 
support. Low parental support did not predict increases in externalizing or substance abuse symptoms. These results suggest that for girls during middle adolescence, externalizing problem behavior is a more consistent predictor of parental support than parental support is of externalizing problem behavior.

Only one study was found that reported full reciprocal effects between parental support and adolescent externalizing problems. Stice \& Barrera (1995) used covariance structural modeling to examine prospective reciprocal relations between perceived parenting and adolescents' substance use and externalizing symptoms among a community sample of adolescents and their parents, within which half of the adolescents were at risk for problem behavior because of parental alcoholism. Full reciprocal relations between adolescent self-reported substance use and levels of parental support were found: higher substance use predicted less support over time and higher support predicted less substance use over time. Also, adolescent self-reported externalizing behaviors prospectively predicted parental support, with higher levels of externalizing leading to less parental support. Parental support was not prospectively related to externalizing behavior, however. These findings support the reciprocal effects model for substance use and the support erosion model for externalizing behavior.

In sum, empirical evidence so far suggests a direct effects model of parental support on internalizing behavior, a child effects model of externalizing behavior on parental support characterized by support erosion, and a reciprocal effects model for substance use. As many studies did not use a full reciprocal model to test for effects between parental support and problem behavior, further research is needed to confirm these findings. At the Adolescent Development Research Centre we have also examined bidirectional effects between parental support and various types of problem behavior, covering an age period from early adolescence until early adulthood. In the remaining part of this chapter we will describe the results of several of these studies.

\section{LONGITUDINAL ASSOCIATIONS BETWEEN PARENTAL SUPPORT AND INTERNALIZING AND EXTERNALIZING BEHAVIOR DURING ADOLESCENCE}

Using data from the second and third wave of the CONAMORE (CONflict And Management Of RElationships, Meeus et al., 2004) longitudinal study, Hale III et al. (2005) examined longitudinal bidirectional effects between parental support and internalizing behavior during adolescence. In this study, conflict with parents was also included, so findings for conflict will also be presented. For the current chapter we repeated these analyses for externalizing behavior. We hypothesized that parental support would predict lower levels 
of internalizing problems and that externalizing behavior would predict less parental support over time. As some studies found that stronger effects of parental support for females than for males, we also explored gender differences in the associations between parental support and problem behavior. Of the 1313 adolescents who longitudinally participated in the CONAMORE study, 1185 (578 boys, 607 girls) had complete data on all the measures used in the current study. Of these 1185 adolescents, 841 were early adolescents (13-14 years in wave 2) and 344 were middle adolescents (17-18 years in wave 2). $86 \%$ of the adolescents were of Dutch origin; the other $14 \%$ came from other ethnic minorities.

Perceived support from mother and father and conflict with mother and father were measured using the short version of the Network of Relationship Inventory (Furman \& Buhrmester, 1992). The participants indicated on a fivepoint Likert scale (ranging from $1=a$ little or not at all, $5=$ more is not possible) the amount of support they received from their parents and the frequency of conflict in the relationship with their parents, for the relationships with their mother and father separately. Examples of items are: "Does your mother/father like or approve of the things you do?" (support), and "Do you and your mother/father get on each other's nerves?" (conflict). Internal consistencies were high with alphas ranging from .87 to .92.

Internalizing problems consisted of a measure for depression and anxiety. Depression was measured with the Children's Depression Inventory (CDI) (Kovacs, 1985), a symptom-based measure consisting of 27 items rated on a three-point Likert scale ranging from not true to very true. Sample items are: "I worry all the time about all kind of things", "I feel tired all the time", and "I don't have any friends." Cronbach's alpha for this measure in the current sample was 0.92. Anxiety was measured with the SCARED (Screen for Child Anxiety Related Emotional Disorders) (Birmaher et al., 1997), a reliable and valid DSM-IV-related self-report questionnaire (Birmaher et al., 1999; Hale III et al., 2005). The SCARED includes subscales for panic disorder (e.g., "When I am scared I have difficulties with breathing"), separation anxiety (e.g., "I worry that something bad will happen to my parents"), social anxiety (e.g., "I feel nervous around people I don't know well"), school anxiety (e.g., "I worry about going to school"), and generalized anxiety (e.g., "I worry if I am going to be fine"). Items were rated on a three-point scale: 0 (almost never), 1 (sometimes), 2 (often), and were averaged to compute a total anxiety score. Cronbach's alpha for this scale was 0.93 .

Externalizing problems contained a scale for aggression and delinquency. Aggression was measured by the Direct and Indirect Aggression Scales (DIAS) (Björkqvist, Lagerspetz, \& Osterman, 1992). We used the 17 items from the subscales for direct aggression (e.g., "I kick or strike the other one" or "I call the other one names") and indirect aggression (e.g., "I spread vicious rumors as revenge" or "I tell others not to associate with that person"), which have good reliability (Björkqvist, Lagerspetz, \& Osterman, 1992). Adolescents 
indicated on a four-point Likert scale ranging from never to very often the extent to which they show certain behaviors when they are angry at someone in the classroom. A total aggression score was computed by averaging direct and indirect aggression scores $(\alpha=0.89)$. Delinquency was measured by a 16- item minor delinquency questionnaire (Baerveldt, van Rossem, \& Vermande, 2003). Adolescents were asked to rate on a four-point scale ranging from never to four times or more how often they had shown certain forms of delinquent behavior (e.g., "stolen a bike", "deliberately broken something on street") during the last 12 months. This measure has good internal consistency and is sufficiently onedimensional (Baerveldt, van Rossem, \& Vermande, 2003). Cronbach's alpha in the current sample was 0.90 .

Latent path analyses were conducted using Structural Equation Modeling (AMOS), in which paternal and maternal support were indicators of a latent parental support factor, conflicts with father and mother were indicators of a latent conflict with parents factor, anxiety and depression were indicators of a latent internalizing problems factor, and aggression and delinquency were indicators of a latent externalizing problems factor. Bidirectional effects over time were estimated between support, conflict, and problem behavior, thereby controlling for time 1 correlations, stability, and correlated change of support, conflict, and problem behavior (see Figure 6.1). Fit indices are displayed in Table 6.2 and results are displayed in Table 6.3.

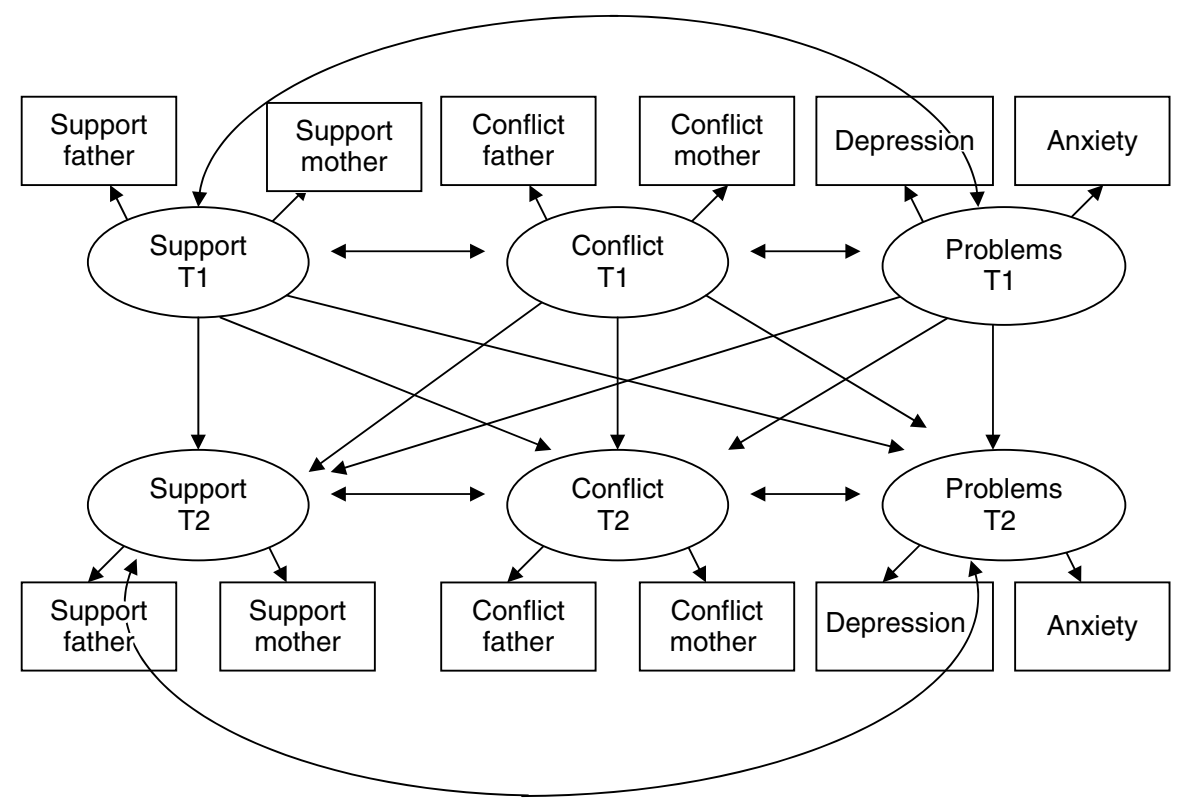

Figure 6.1 Estimated model of parental support, conflict with parents and problem behavior 
Table 6.2 Model fit summary for path analyses

\begin{tabular}{lccccc}
\hline Model & $\chi^{2}$ & $d f$ & NNFI & CFI & RMSEA \\
\hline Externalizing & $213.12^{* *}$ & 36 & 0.91 & 0.95 & 0.08 \\
Internalizing & $175.48^{* *}$ & 36 & 0.94 & 0.97 & 0.07 \\
Internalizing multigroup: & & & & & \\
1. invariant & $751.15^{* *}$ & 220 & 0.90 & 0.92 & 0.05 \\
2. different paths & $693.57^{* *}$ & 193 & 0.89 & 0.92 & 0.05 \\
3. diff paths boys v. girls & $\mathbf{7 2 1 . 1 8}^{* *}$ & $\mathbf{2 1 1}$ & $\mathbf{0 . 9 0}$ & $\mathbf{0 . 9 2}$ & $\mathbf{0 . 0 5}$ \\
4. diff paths young v. old & $741.75^{* *}$ & 211 & 0.90 & 0.92 & 0.05 \\
\hline
\end{tabular}

** $p<0.01$

Table 6.3 Correlations and effects among parental support, parental conflict, and problem behavior

\begin{tabular}{|c|c|c|c|c|}
\hline & \multirow{2}{*}{$\frac{\text { Externalizing }}{\text { Total sample }}$} & \multicolumn{3}{|c|}{ Internalizing } \\
\hline & & Total sample & Girls & Boys \\
\hline \multicolumn{5}{|l|}{ Time 1 correlations } \\
\hline Support - conflict & $-0.53^{* *}$ & $-0.52^{* *}$ & $-0.58^{* *}$ & $-0.58^{* *}$ \\
\hline Conflict - problem behavior & $0.62^{* *}$ & $0.48^{* *}$ & $0.54^{* *}$ & $0.54^{* *}$ \\
\hline $\begin{array}{l}\text { Support - problem } \\
\text { behavior }\end{array}$ & $-0.29^{* *}$ & $-0.24^{* *}$ & $-0.33^{* *}$ & $-0.33^{* *}$ \\
\hline \multicolumn{5}{|l|}{ Time 2 correlations } \\
\hline Support - conflict & $-0.35^{* *}$ & $-0.33^{* *}$ & $-0.47^{* *}$ & $-0.47^{* *}$ \\
\hline Conflict - problem behavior & $0.44^{* *}$ & $0.32^{* *}$ & $0.32^{* *}$ & $0.32^{* *}$ \\
\hline $\begin{array}{l}\text { Support - problem } \\
\text { behavior }\end{array}$ & $-0.28^{* *}$ & $-0.20^{* *}$ & $-0.30^{* *}$ & $-0.30^{* *}$ \\
\hline \multicolumn{5}{|l|}{ Regression Weights $(\beta)$} \\
\hline Support $\mathrm{t} 1$ - support $\mathrm{t} 2$ & $0.67^{* *}$ & $0.67^{* *}$ & $0.69^{* *}$ & $0.69^{* *}$ \\
\hline Conflict $\mathrm{t} 1-$ conflict $\mathrm{t} 2$ & $0.76^{* *}$ & $0.70^{* *}$ & $0.73^{* *}$ & $0.81^{* *}$ \\
\hline $\begin{array}{l}\text { Problem behavior } \mathrm{t} 1- \\
\text { problem behavior } \mathrm{t} 2\end{array}$ & $0.75^{* *}$ & $0.71^{* *}$ & $0.84^{* *}$ & $0.61^{* *}$ \\
\hline Support t 1 - conflict t 2 & 0.02 & 0.02 & 0.01 & $0.16^{*}$ \\
\hline Conflict $\mathrm{t} 1$ - support $\mathrm{t} 2$ & -0.06 & -0.05 & -0.06 & 0.09 \\
\hline $\begin{array}{l}\text { Support } \mathrm{t} 1-\text { problem } \\
\text { behavior } \mathrm{t} 2\end{array}$ & -0.10 & 0.02 & -0.00 & -0.00 \\
\hline $\begin{array}{l}\text { Conflict } \mathrm{t} 1-\text { problem } \\
\text { behavior } \mathrm{t} 2\end{array}$ & -0.06 & -0.01 & -0.12 & 0.11 \\
\hline $\begin{array}{l}\text { Problem behavior } \mathrm{t} 1 \text { - } \\
\text { conflict } \mathrm{t} 2\end{array}$ & -0.02 & $0.11^{*}$ & 0.05 & 0.08 \\
\hline $\begin{array}{l}\text { Problem behavior } \mathrm{t} 1 \text { - } \\
\text { support } \mathrm{t} 2\end{array}$ & -0.05 & $-0.10^{*}$ & -0.05 & $-0.14^{*}$ \\
\hline
\end{tabular}

${ }^{*} p<0.05 ;{ }^{* *} p<0.01$

Parental support was found to be negatively associated with internalizing and externalizing behavior at time 1 and time 2. Higher levels of parental support were related to lower levels of externalizing and internalizing problems ( $r=-0.29$ and -0.24 , respectively), and a greater decrease in 
parental support was related to a greater increase in externalizing and internalizing problem behavior $(r=-0.28$ and -0.20 , respectively). In contrast to our hypothesis, no cross-lagged effects between parental support and externalizing problem behavior were found. For internalizing behavior, we found an effect on parental support and conflict with parents, but again this effect disconfirmed our hypothesis: adolescents who had higher internalizing problems at time 1 perceived less support and more conflict with parents at time 2 ( $\beta=-0.10$ and 0.11 , respectively). We examined sex and age differences in this effect using multigroup models. Chi-square difference tests revealed that a model with sex differences and no age differences between early and middle adolescents in cross-lagged paths provided the best fit to the data. Estimates for this model showed that the detrimental effect of internalizing problems for parental support were significantly stronger for boys than for girls (see Figure 6.2).

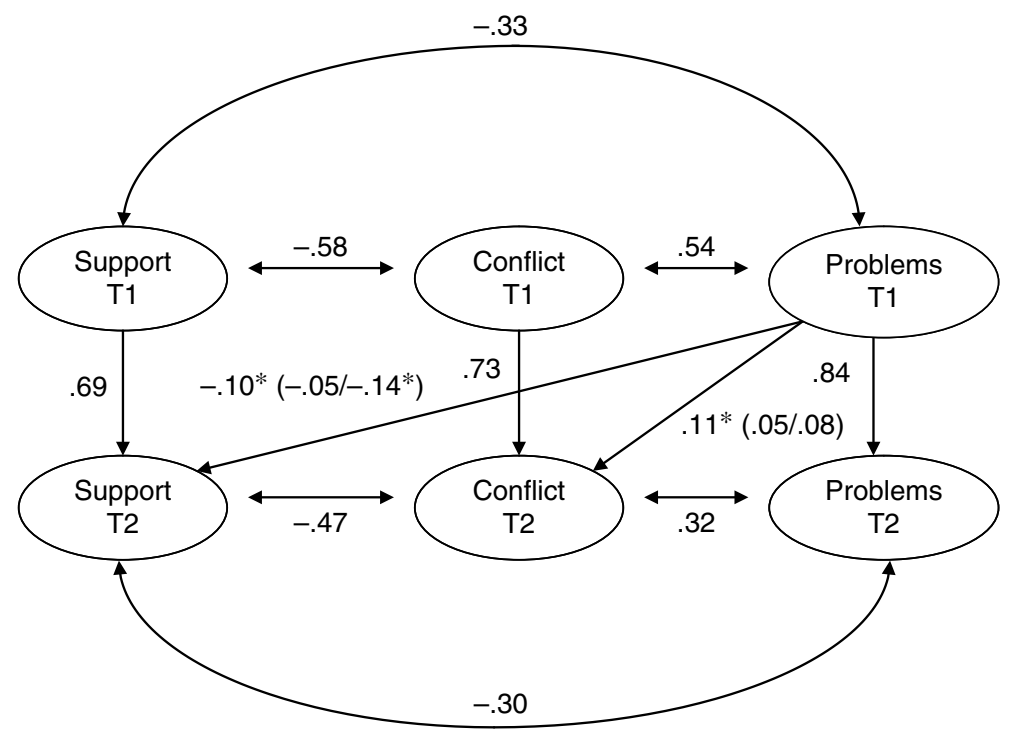

Figure 6.2 Associations between parental support, conflict with parents, and internalizing problem behavior over time

\section{LONGITUDINAL ASSOCIATIONS BETWEEN PARENTAL SUPPORT AND INTERNALIZING AND EXTERNALIZING BEHAVIOR DURING ADOLESCENCE AND YOUNG ADULTHOOD}

In two studies, we examined the bidirectional associations of parental support with internalizing behavior (i.e., emotional problems) and externalizing 
behavior (i.e., delinquency) in the context of adolescents' and young adults' romantic relationships. Both studies used data from the Utrecht Study of Adolescent Development (USAD) 1991-1997 (Meeus \& 't Hart, 1993; see the study of Helsen, Vollebergh, \& Meeus, 2000, described earlier). The development of intimacy and commitment to romantic partners is one of the important tasks for adolescents and young adults (Erikson, 1968), although relations with parents and friends remain important for support and intimacy (Seiffge-Krenke, 1997; Shulman \& Scharf, 2000). As romantic partners become more important both with age and with extended experience with romantic partners (Shulman \& Scharf, 2000), they will eventually replace the parent as the most important attachment figure (Hazan \& Shaver, 1987). Thus, it might be that parental support is no longer related to emotional problems when adolescents and adults have a romantic partner. This effect might be stronger for young adults who have more mature romantic relationships.

Similarly, it has been found that once young adults have a romantic partner, their parents no longer have any influence on their delinquency and the quality of the relationship with the romantic partner is predictive of delinquency (see for an overview Meeus, Branje, \& Overbeek, 2004). Studies that only considered the association between the relationship with parents and delinquency did report an association between the quality of the relationship with parents and delinquency. However, these studies only focused on adolescence and not on young adulthood (i.e., after 20 years of age). The difference between these studies might be due to a moderation effect of having a romantic partner on the association between the relationship with parents and delinquency, but could also reflect that the influence of parents diminishes as the adolescent grows older regardless of partnership status.

We investigated how involvement with romantic partners moderates the effect of parental support on delinquency and emotional problems. We expected that parental support is predictive of the degree of delinquency and emotional problems when adolescents have no romantic partners but not predictive if they do have such a partner. We also expected that for adolescents with romantic involvement, parental support is stronger related to less delinquency and emotional problems than for young adults because romantic partners are thought to become more important and effects of parental support might diminish with age.

As the effects of romantic partner might be especially strong when there is extended experience with romantic partners, we distinguished three partnership status groups: (1) Six year partner group: respondents who have had a romantic partner at time 1 and time 2 six years later, and consequently had experience with one or more partners for a period that spanned, although not necessarily continuously, a period of six years, (2) T2 partner group: respondents who moved from having no partner at time 1 to having a partner at time 2, (3) Never partner group: respondents who never had a partner. Respondents who did not fall into one of these patterns were excluded from the study. In order to examine whether the diminished influence of the parents could be 
attributed to the existence of a romantic partner or to age alone, we distinguished adolescents (aged 12-18 in wave 1) and young adults (aged 21 in wave 1).

\section{LONGITUDINAL EFFECTS BETWEEN PARENTAL SUPPORT AND DELINQUENCY}

The first study examines how romantic involvement moderates the effect of parental support on delinquency. Meeus, Branje \& Overbeek (2004) used the same three partner groups of the USAD study to examine longitudinal associations between parental support and delinquency. Parental support was the average of paternal and maternal support. Partner support was assessed by means of a list of three questionnaire items. Respondents indicated on a 10-point scale (range 10-100) the degree of social support they received in the domain of personal relationships, leisure time and school/work from their romantic partner. Cronbach's alphas for partner support were 0.82, 0.75, and 0.74 at wave 1 , wave 2 and wave 3 respectively. Delinquency was assessed in an oral interview as the number of delinquent acts the respondents reported over the past 12 months. The delinquency measure consists of 21 items pertaining to three types of delinquent behavior: violent crime (e.g., "Have you ever wounded anybody with a knife or other weapon?"), vandalism (e.g., "Have you ever covered walls, buses, or entryways with graffiti?"), and crime against property (e.g., "Have you ever bought something which you knew was stolen?"). Subjects indicated whether they had behaved in one of these ways during the past 12 months on a two-point scale $(0=$ no, to $1=$ yes). The scores on the 21 items were summed with ranges between $0-10$ in wave $1,0-9$ in wave 2, and 0-6 in wave 3; mean scores were $0.81,0.70$ and 0.48 respectively. In the structural equation models standardized scores were used. Results are displayed in Figures 6.3a-6.3c.

Multigroup path analyses (with six groups: three partner groups by two age groups) revealed that parental support was related to a reduction in the level of delinquency over time for adolescents and young adults who have never had a partner and for adolescents who only have a partner at time 2 six years later. For these adolescents and young adults, higher levels of parental support were associated with lower levels of delinquency six years later. For adolescents and young adults who consistently had a romantic partner across the waves and for young adults who moved into a relationship with an romantic partner, parental support was not related to a reduction of delinquency over time. Furthermore, delinquency was found to lead to reduced parental support for adolescents and young adults who had a romantic relationship at time 2 only, but not for any of the other groups of adolescents. These findings show that delinquency can be an obstacle for maintaining good relationships with parents. 


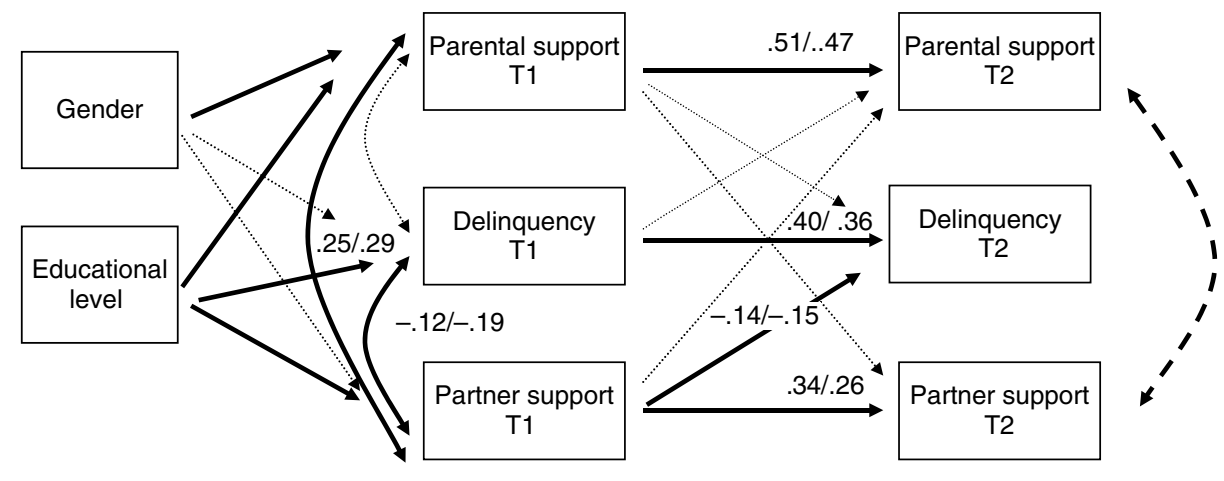

(a)

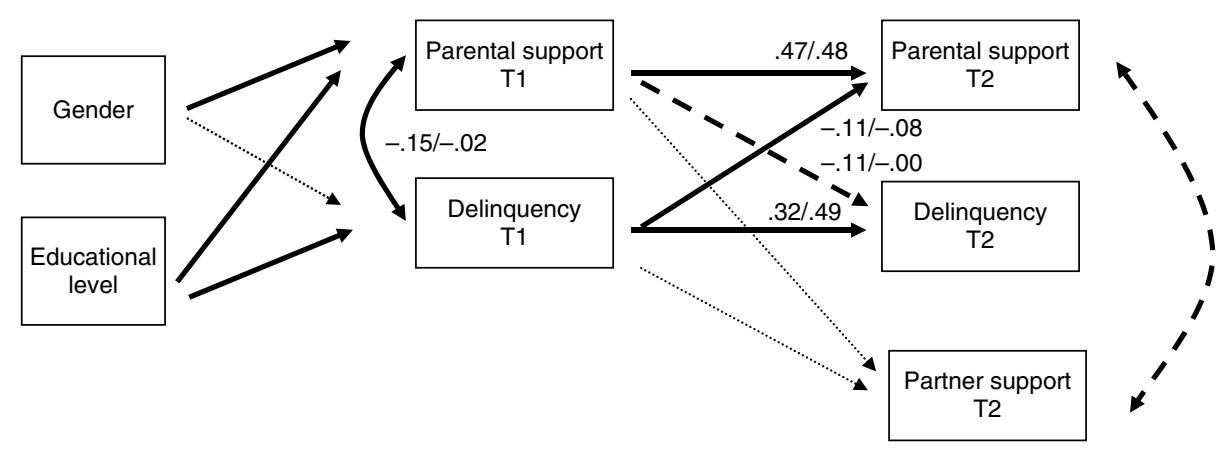

(b)

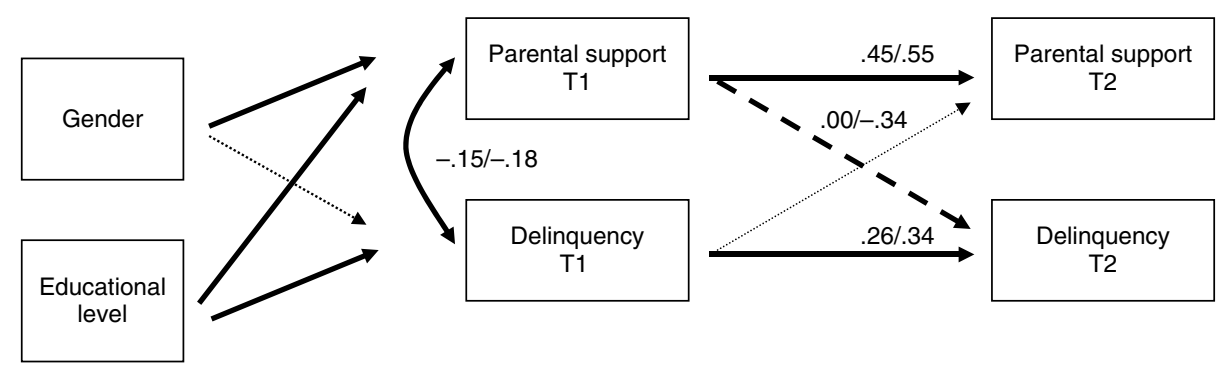

(c)

Figure 6.3 Models of relations between parental support and delinquency for the systematic romantic partner groups (a), the best friend to romantic partner groups (b), and no romantic partner groups (c). Statistics of the relevant significant parameters of both age groups within the relationship status groups are printed. The first statistic is that of the youngest group, the second that of the oldest. Only significant estimates are shown. Broken lines indicate correlations or paths that were significant in only one group 
In sum, these findings offer evidence for the moderating role of the relationship with a romantic partner on the effects of parental support on delinquency. In adolescents and young adults who have a romantic partner, parental support is not important in reducing delinquency and partners seem to have taken this role from parents. For adolescents and young adults who have never had a partner, as well as for adolescents who do not have a partner yet, parental support is important in reducing delinquency. Confirming our expectations regarding age, adolescents who are on their way to finding a romantic partner are still influenced by parental support, whereas young adults who are forming relationships with romantic partners are not affected in this stage of their lives by parental support.

\section{LONGITUDINAL EFFECTS BETWEEN PARENTAL SUPPORT AND EMOTIONAL PROBLEMS}

The second study describes how involvement with romantic partners moderates the effect of parental support on emotional adjustment. Meeus et al. (in press) examined longitudinal associations of parental support with emotional problems as part of a study on longitudinal relations of parental support and emotional adjustment with commitment to romantic partners and best friends. The longitudinal sample consisted of 1,302 participants, of whom 550 were males. The respondents were evenly distributed over four age categories: 321 early adolescents (25\%), 341 middle adolescents (26\%), 261 late adolescents (20\%), and 379 young adults (29\%). For this study, the three youngest age groups were combined to create one adolescent group.

Parental support was computed as the average of support of father and mother (see also Helsen, Vollebergh, \& Meeus, 2000). Cronbach's alphas for parental support were $0.87,0.88$, and 0.87 at wave 1 , wave 2 , and wave 3 respectively. Emotional adjustment was assessed as a composite of scales for psychological stress and depression, general well being and happiness, and the consideration of suicide (see also Helsen, Vollebergh, \& Meeus). Relational commitment to best friend and romantic partner was assessed with the relational commitment scale of the Utrecht-Groningen Identity Development Scale (U-GIDS) (Meeus, 1996). Adolescents who had a romantic partner rated this partner, other adolescent rated a best friend. The sixitem scale includes items tapping commitment to stay in the relationship and involvement in the relationship. Examples of the items are: "My best friend/romantic partner allows me to face the future with optimism' (intent to persist in the relationship"), and "I'm sure my best friend/romantic partner was the best choice for me" (psychological attachment to the relationship). A five-point Likert type scale was used with response categories ranging from $1=$ "completely untrue" to $5=$ "completely true." Cronbach's alphas of the scale for relational commitment were $0.88,0.89$, and 0.89 at wave 1 , wave 2 , and wave 3 respectively. 


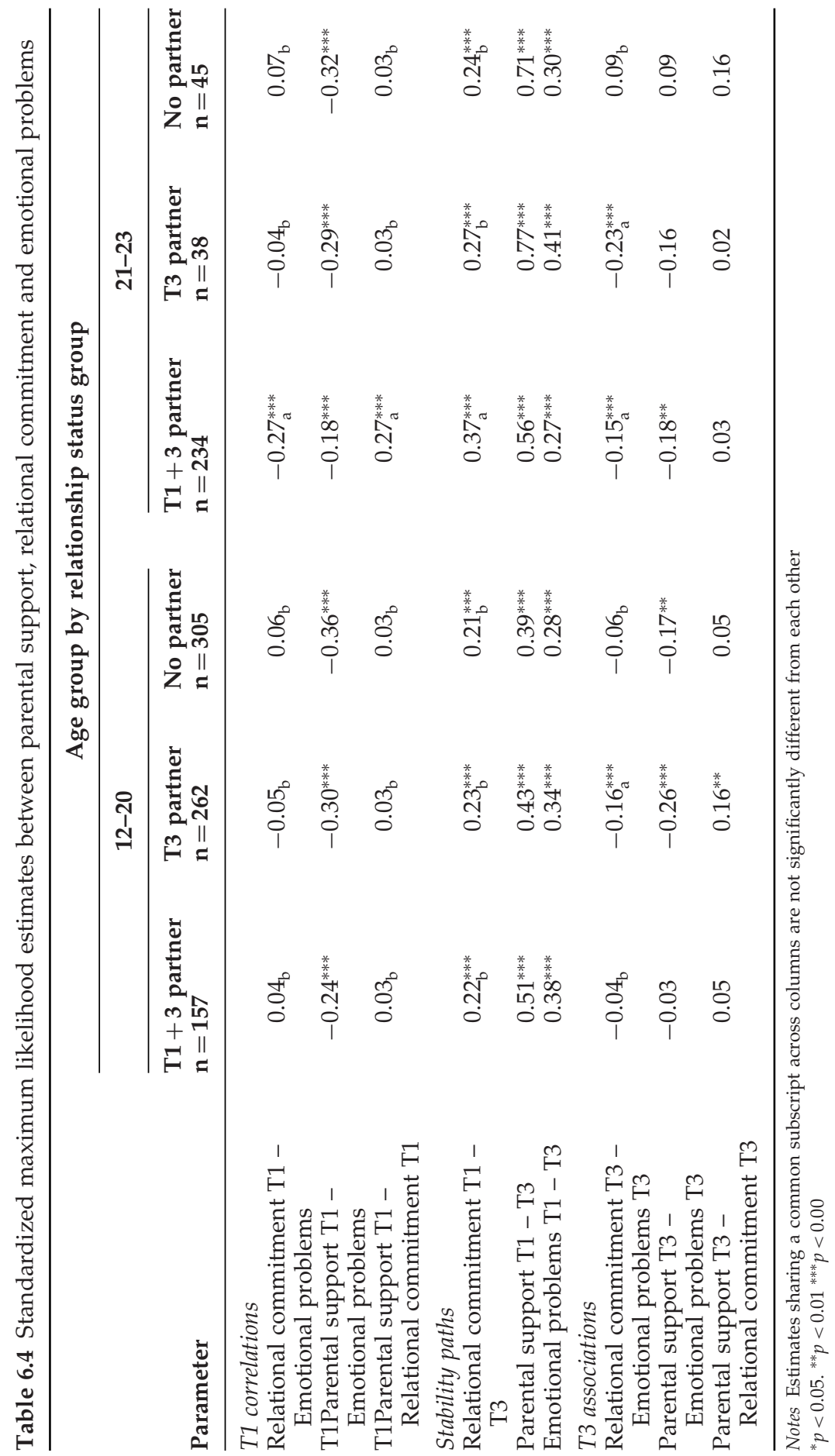


We performed multigroup path analyses using AMOS to estimate links over time between parental support, partner/best friend commitment and emotional problems for the six groups of adolescents and young adults with and without a romantic partner (three partner status groups by two age groups). Results of this study are displayed in Table 6.4.

Results showed that parental support was related to less emotional disturbance at time 1 for all groups, and that this relation is stronger for adolescents without a romantic partner than for adolescents with a romantic partner. At time 2, there was correlated change between parental support and emotional problems: a decline in parental support was related to an increase in emotional problems for young adults with a romantic partner at both time points, for adolescents without a partner, and for adolescents with a partner at time 2 only (that are late adolescents or young adults by this time). Against our expectation, there were no crosslagged effects from parental support to emotional problems or from emotional problems to parental support for any of the groups. These findings suggest that parental support is more strongly related to emotional problems for adolescents than for young adults, however when young adults are systematically involved in romantic relationships, parental support is related to emotional problems as well. Thus, disconfirming our hypothesis, romantic partners only partially take over the role of parents in young adulthood. An explanation for this findings might be that relationships with parents become more egalitarian when adolescents are older and parents are more likely to be accepted as supportive when dealing with romantic relationships in young adulthood than in adolescence.

\section{DISCUSSION}

The aim of this chapter was to compare longitudinal evidence for associations between parental support and adolescent problem behavior to theoretical perspectives that offer explanations for these associations. Theoretical perspectives focusing on direct effects of parent, direct effects of child, and reciprocal effects were compared. Longitudinal results confirm the importance of assessing bidirectional effects and generally suggested that parental direct effects are found predominantly for internalizing problems, whereas child direct effects or bidirectional effect are more likely to occur for externalizing problems. The review of empirical findings confirms that parents play a pronounced role in adolescent adjustment, particularly in internalizing problems (Baumrind, 1991). Adolescents rely on parents to provide several types of support (Furman \& Buhrmester, 1992), and they might be deeply effected by a lack of parental support because of the permanent nature of the parent-child relationship (Collins \& Laursen, 1992).

For both depression and anxiety, most support was found for direct effects of parental support. These effects were more often found for adolescents than for young adults and when gender differences were found, effects tended 
to be stronger for girls. Youth who experience deficits in parental provision of support seem to be more likely to feel depressed. Although these results suggest that parental support promotes ways of coping in adolescents that enables them to deal more effectively with problems or daily hassles and may help them to regulate their emotional states (Eisenberg \& Fabes, 1992; Wills \& Cleary, 1996), not much support was found for stress-buffering effects of parental support, although the possibility remains that parental support compensates for other (unidentified) vulnerability factors. Also, only limited evidence was found for erosion of parental support as a consequence of effects in reaction to adolescent depressive and anxiety symptoms. Perhaps internalizing problems are more likely to promote erosion of support in relationships with peers that are more voluntary than in relationships with parents (Stice, Ragan, \& Randall, 2004). Surprisingly, the results of our own studies are not in agreement with these general findings. In one study we did not find effects over time between parental support and emotional problems, in the other study we found evidence for support erosion, in particular for boys with internalizing problems. One reason for this unexpected finding is that, until now, hardly any studies have examined reciprocal effects between support and internalizing behavior for girls and boys separately. This finding might reflect that parents accept internalizing behavior less from boys than from girls and reduce their support to boys but not to girls in response to internalizing behavior.

For externalizing behavior, longitudinal results most consistently revealed evidence for adverse effects of adolescent problem behavior on parental support, indicating that parents tend to detach emotionally from their externalizing adolescent and reduce their support to the adolescent as a consequence of the externalizing behavior. Although there was less support for the assertion that deficits in parental support unilaterally foster adolescent problem behaviors, reciprocal effects were also found, in particular for substance use. These effects suggest cycles of influence in which youths prone to externalizing behavior repulse their parents because of their problem behavior (Patterson et al., 1998) and the adolescents subsequently use illicit substances or display acting-out behavior as a means of coping with this perceived deficit in parental support. Again, our own results were not in agreement with these conclusions. One study did not reveal effects over time between externalizing behavior and parental support; the other study showed that parental support was related to delinquency but only for adolescents who had a romantic partner in late adolescence only (time 2 of the study) and for young adults who did not have a romantic partner during the study. Further research is needed to see if reciprocal effects between parental support and externalizing behavior will be found when controlling for initial relationships, stability, and correlated change.

The findings discussed in this chapter demonstrate that longitudinal relations of parental support with internalizing and externalizing problems are not the same under all conditions. The precise pattern of effects between 
parental support and adjustment problems for adolescents might depend on a number of factors, including adolescents' individual characteristics (e.g., ethnicity, sex, age) and types of problem behaviors (e.g., depression, anxiety). Also, social support may be provided by peers, teachers, mentors, and other persons in the network of youngsters, and effects of parental support can have a differential impact in the context of other relations, such as siblings (Branje et al., 2004), romantic partners (Meeus et al., 2004, in press), and friends (Young et al., 2005).

The extent to which parental support and child problem behavior affect each other might depend on the developmental period under study. During childhood, parental effects might be larger than during adolescence, whereas during adolescence child effects might be larger than during childhood. Additionally, when both problem behavior and parental support are stable over time it is likely that reciprocal influences between problems and support have been established during childhood and remain stable over time. Therefore, few reciprocal effects will be observed. Effects might further decrease during late adolescence, when adolescents move out of their parents' home, either to continue their education or begin their own families, and peer support may become more important than parental support (Furman \& Buhrmester, 1992; Helsen, Volleburgh, \& Meeus, 2000; Wilkinson, 2004). The vanishing effect of support from parents as adolescents age into adulthood (Meadows, Brown, \& Elder, 2006; Meeus, Branje, \& Overbeek, 2004) might reflect the changing role of parents during the transition to adulthood when adolescents begin to establish independent lives (Helsen, Vollebergh \& Meeus, 2000; Furman \& Buhrmester, 1992).

The findings presented in this chapter seem consistent with the assertion that parents continue to affect adolescent development (Collins et al., 2000). Nevertheless, third variables may be involved that are not included in the study and influence the relations between problem behavior and perceived support. An example of such a third variable is genetic resemblance between family members. Because parents and children are genetically related, the relations between parental support and adolescent adjustment problems might in part be explained by genetic similarity between parents and children (Caspi, 2000). Genetic factors that influence parents' ability to provide support to their children might be the same as the genetic factors accounting for child problem behavior (Harris, 1998; Jaffee et al., 2004).

Moreover, most studies have assessed adolescents' perceived parental support and thus effects between parental support and adolescent problem behavior might exist in the eye of the beholder: adolescents with higher levels of problems might perceive their environment differently than adolescents with lower levels of problems. The correlations between reports of parents and adolescents on parental support are not very high and mean levels substantially differ. Perceiver effects play a relatively strong role in adolescents' perceptions of support from fathers and mothers (Branje, Van Aken, \& Van Lieshout, 2002), indicating that the meanings that adolescents 
make of their experiences with parents are important to understand. Because similar experiences may mean different things to different adolescents, the same experiences may lead to different outcomes for different adolescents. These large perceiver effects might also explain why generally not many differences between effects of paternal support and maternal support are found. Future research should address whether the results for adolescent reported parental support generalize to more "objective" measures of parental support.

To conclude, results suggest that parental effects are found predominantly for internalizing problems, whereas child effects and bidirectional effect are found predominantly for externalizing problems. Future longitudinal research should examine the processes mediating the effects between parental support and problem behavior. Does a lack of parental support lead to ineffective ways of coping (Wills \& Cleary, 1996)? Does lack of parental support interfere with socialization processes and internalization of parental norms (Baumrind, 1991)? Does a lack of parental support lead to externalizing behavior through a process of affiliation with deviant peers (Patterson, 1982; Dishion, Nelson, \& Bullock, 2004)? Or does adolescent problem behavior lead to parent emotional rejection (Baumrind \& Moselle, 1985)? Knowledge of the underlying mechanisms would greatly increase our understanding of the associations between adolescent problem behavior and parental support.

\section{REFERENCES}

Baerveldt, C., Rossem van, R., \& Vermande, M. (2003). Pupils' delinquency and their social networks: a test of some network assumptions of the ability and inability models of delinquency. Netherlands Journal of Social Sciences, 39, 107-125.

Barnes, G. M. \& Farrell, M. P. (1992). Parental support and control as predictors of adolescent drinking, delinquency, and related problem behaviors. Journal of Marriage and the Family, 54, 763-776.

Baumrind, D. (1991). Parenting styles and adolescent development. In J. Brooks-Gunn, R. Lerner \& A. C. Petersen (eds), The Encyclopedia of Adolescence (pp. 746-758). New York: Garland.

Baumrind, D. \& Moselle, K. A. (1985). A developmental perspective on adolescent drug abuse. Advances in Alcohol and Substance Abuse, 4, 41-67.

Beck, A. T., Rush, A. J., Shaw, B. F., \& Emery, G. (1979). Cognitive Therapy of Depression. New York: Guilford Press.

Bell, R. (1968). A reinterpretation of the direction of effects in studies of socialization. Psychological Review, 75, 81-95.

Bell, R. Q. \& Chapman, M. (1986). Child effects in studies using experimental or brief longitudinal approaches to socialization. Developmental Psychology, 22, 595-603.

Belsky, J. (1984). The determinants of parenting: A process model. Child Development, $55,83-97$.

Birmaher, B., Khetarpal, S., Brent, D. et al. (1997). The Screen for Child Anxiety Related Emotional Disorders (SCARED): Scale construction and psychometric characteristics. Journal of the American Academy of Child and Adolescent Psychiatry, 36, 545-553. 
Birmaher, B., Brent, D. A., Chiappetta, L. et al. (1999), Psychometric properties of the Screen for Child Anxiety Related Emotional Disorders (SCARED): A replication study. Journal of the American Academy of Child and Adolescent Psychiatry, 38, 1230-1236.

Bjorkqvist, K., Lagerspetz, K. M. J., \& Osterman, K. (1992). The Direct and Indirect Aggression Scales. Vasa, Finland: Abo Akademi University, Department of Social Sciences.

Branje, S. J. T., Van Aken, M. A. G., \& Van Lieshout, C. F. M. (2002). Relational support in families with adolescents. Journal of Family Psychology, 16, 351-362.

Branje, S. J. T., Van Lieshout, C. F. M., Van Aken, M. A. G ., \& Haselager, G. J. T. (2004). Perceived support in sibling relationships and adolescent adjustment. Journal of Child Psychology and Psychiatry, 45, 1385-1396.

Burton, E., Stice, E. \& Seeley, J. R. (2004). A prospective test of the stress-buffering model of depression in adolescent girls: No support once again. Journal of Consulting and Clinical Psychology, 72, 689-697.

Caspi, A. (2000). The child is father of the man: personality continuities from childhood to adulthood. Journal of Personality and Social Psychology, 78, 158-172.

Cohen, S. \& Wills, T. A. (1985). Stress, social support, and the buffering hypothesis. Psychological Bulletin, 98, 310-357.

Collins, W. A. \& Laursen, B. (1992). Conflict and relationships during adolescence. In C. U. Shantz \& W. W. Hartup (eds), Conflict in Child and Adolescent Development (pp. 216-241). New York: Cambridge University Press.

Collins, W., Maccoby, E. E., Steinberg, L. et al. (2000). Contemporary research on parenting: the case for nature and nurture. American Psychologist, 55, 218-232.

Coyne, J. C. (1976). Depression and the response of others. Journal of Abnormal Psychology, 85, 186-193.

Coyne, J. C., Burchill, S. A. L. \& Stiles, W. B. (1991). An interactional perspective on depression. In C. R. Snyder \& D. O. Forsyth (eds), Handbook of Social and Clinical Psychology (pp. 327-349). New York: Pergamon.

Deković, M., Janssens, J. M. A. M \& Van As, N. M. C. (2003). Family predictors of antisocial behavior in adolescence. Family Process, 42, 223-235.

Dishion, T. J., Nelson, S. E., \& Bullock, B. M. (2004). Premature adolescent autonomy: Family management and deviant peer process in the amplification of problem behavior. Journal of Adolescence, 27, 515-530.

DuBois, D. L., Felner, R. D., Brand, S. et al. (1992). A prospective study of life stress, social support, and adaptation in early adolescence. Child Development, 63, 542-557.

Eisenberg, N. \& Fabes, R. A. (1992). Emotion, regulation, and the development of social competence. In S. C. Margaret (ed.), Emotion and Social Behavior. Review of Personality and Social Psychology: Vol. 14 (pp. 119-150). Newbury Park, CA: Sage.

Erikson, E. (1968). Identity, Youth and Crisis. New York: Norton.

Fisher, C. S. (1982). To Dwell Among Friends. Personal Networks in Town and City. Chicago University Press, Chicago.

Furman, W. \& Buhrmester, D. (1992). Age and sex differences in perceptions of networks of personal relationships. Child Development, 63, 103-115.

Ge, X., Lorenz, F. O., Conger, R. D. et al. (1994) Trajectories of stressful life events and depressive symptoms during adolescence. Developmental Psychology, 30, 467-483.

Hale III, W. W. (2001). Behavioral social support between remitted depressed patients with partners and strangers. Journal of Affective Disorders, 64, 285-289. 
Hale III, W. W., Branje, S. J. T., Raaijmakers, Q. A. W., \& Meeus, W. H. J. (2005). Why Me? Adolescent Problems and Parental Support and Conflict. Symposium paper presented at the Twelfth European Conference on Developmental Psychology, Tenerife, Spain, August 24-27, 2005.

Hale III, W. W., Raaijmakers, Q., Muris, P., \& Meeus, W. (2005). Psychometric properties of the Screen for Child Anxiety Related Emotional Disorders (SCARED) in the general adolescent population. Journal of the American Academy of Child and Adolescent Psychiatry, 44, 283-290.

Hale III, W. W., Van der Valk, I., Akse, J., \& Meeus, W. (in press). The interplay of early adolescent depressed mood, aggressive behavior and perceived parental rejection: A four year longitudinal community study.

Harris, J. R. (1998). The Nurture Assumption: Why Children Turn Out the Way They Do. New York: Free Press.

Hartup, W. W. (1978). Perspectives on child and family interaction: Past, present, and future. In R. M. Lerner \& G. B. Spanier (eds), Child Influences on Marital and Family Interaction: A Life-Span Perspective (pp. 23-46). San Francisco: Academic Press.

Haselager, G. J. T. \& Van Aken, M. A. G. (1999). Codebook of the Research Project Family and Personality: Vol. 1. First Measurement Wave. Nijmegen, The Netherlands: University of Nijmegen, Faculty of Social Science.

Hazan, C. \& Shaver, P. (1987). Romantic love conceptualized as an attachment process. Journal of Personality and Social Psychology, 52, 511-524.

Helsen, M., Vollebergh, W., \& Meeus, W. (2000). Social support from parents and friends and emotional problems in adolescence. Journal of Youth and Adolescence, 29, 319-335.

Hirschi, T. (1969). Causes of Delinquency. Berkeley, CA: University of California Press.

Hollon, S. D. \& Beck, A. T. (1994) Cognitive and cognitive-behavioral therapies. In A. E. Bergin \& S. L. Garfield (eds), Handbook of Psychotherapy and Behavior Change (4th edn, pp. 428-466). Chichester: John Wiley \& Sons.

Huh, D., Tristan, J., Wade, E., \& Stice, E. (2006). Does problem behavior elicit poor parenting? A prospective study of adolescent girls. Journal of Adolescent Research, 21, 185-204.

Jaffee, S. R., Polo-Tomas, M., Taylor, A. et al. (2004). The limits of child effects: Evidence for genetically mediated child effects on corporal punishment but not on physical maltreatment. Developmental Psychology, 40, 1047-1058.

Joiner, T. E. (1999). A test of interpersonal theory of depression in youth psychiatric inpatients. Journal of Abnormal Child Psychology, 27, 77-85.

Kerr, M. \& Stattin, H. (2003). Parenting of adolescents: Action or reaction? In A. C. Crouter \& A. Booth (eds), Children's Influence on Family Dynamics: The Neglected Side of Family Relationships (pp. 121-152). Mahwah, NJ: Erlbaum.

Kovacs, M. (1985). The children's depression inventory. Psychopharmacology Bulletin, 21, 995-998.

Lollis, S. \& Kuczynski, L. (1997). Beyond one hand clapping: Seeing bidirectionality in parent-child relations. Journal of Social and Personal Relationships, 14, $441-461$.

Lopez, E. E., Olaizola, J. H., Ferrer, B. M \& Ochoa, G. M. (2006). Aggressive and nonaggressive rejected students: An analysis of their differences. Psychology in the Schools, 43, 387-400.

Maccoby, E. E. (1984). Socialization and developmental change. Child Development, 55, 317-328.

Maton, A. \& Zimmerman, K. I. (1992). Life-style and substance use among male African-American urban adolescents: A cluster analytic approach. American Journal of Community Psychology, 20, 121-138. 
McCarty, C. A., Van der Stoep, A., Kuo, E. S., \& McCauley, E. (2006). Depressive symptoms among delinquent youth: testing models of association with stress and support. Journal of Psychopathology and Behavioral Assessment, 28, 85-93.

Meadows, S. O., Brown, J. S., \& Elder, G. H. (2006). Depressive symptoms, stress and support: Gendered trajectories from adolescence to young adulthood. Journal of Youth and Adolescence, 35, 89-99.

Measelle, J. R., Stice, E., \& Springer, D. W. (2006) A prospective test of the negative affect model of substance abuse: Moderating effects of social support. Psychology of Addictive Behaviors, 20, 225-233.

Meeus, W. (1989). Parental and peer support in adolescence. In Hurrelmann, K. \& Engel, U. (eds), The Social World of Adolescents (pp. 167-185). New York: De Gruyter.

Meeus, W. (1996). Studies on identity development in adolescence: an overview of research and some new data. Journal of Youth and Adolescence, 25, 569-598.

Meeus, W., Akse, J., Branje, S. J. T. et al. (2004). Codeboek van het onderzoeksproject CONflicts and MAnagement of Relationships (CONAMORE). Eerste meetronde: 2001. [Codebook of the research project CONflicts and MAnagement of Relationships (CONAMORE) First wave: 2001.] Unpublished manuscript, Utrecht University, The Netherlands.

Meeus, W., Branje, S. J. T., \& Overbeek, G. J. (2004). Parents and partners in crime: a six year longitudinal study on changes in supportive relationships and delinquency in adolescence and young adulthood. Journal of Child Psychology and Psychiatry and Allied Disciplines, 45, 1288-1298.

Meeus, W. H. J., Branje, S. J. T., Van der Valk, I., \& De Wied, M. (2007). Relationships with intimate partner, best friend, and parents in adolescence and early adulthood: A study of the saliency of the intimate partnership. International Journal of Behavioral Development, 31, 569-580.

Meeus, W. \& 't Hart, H. (1993). Jongeren in Nederland [Young people in the Netherlands]. Amersfoort: Academische Uitgeverij.

Mounts, N. S. (2004). Contributions of parenting and campus climate to freshmen adjustment in a multiethnic sample. Journal of Adolescent Research, 19, 468-491.

Neyer, F. J. \& Asendorpf, J. B. (2001). Personality-relationship transaction in young adulthood. Journal of Personality and Social Psychology, 81, 1190-1204.

Parker, J. S. \& Benson, M. J. (2005). Parent-adolescent relations and adolescent functioning: Self-esteem, substance abuse, and delinquency. Family Therapy, 32, 131-142.

Patterson, G. R. (1982). A Social Learning Approach: III. Coercive Family Process. Eugene, OR: Castalia.

Patterson, G. R., Forgatch, M. S., Yoerger, K. L., \& Stoolmiller, M. (1998). Variables that initiate and maintain an early-onset trajectory for juvenile offending. Development and Psychopathology, 10, 531-547.

Pierce, R., Frone, M., Russell, M. et al. (2000). A longitudinal model of social contact, social support, depression, and alcohol use. Health Psychology, 91, 28-38.

Reis, H. T., Collins, W. A., \& Berscheid, E. (2000). The relationship context of human behavior and development. Psychological Bulletin, 126, 844-872.

Sameroff, A. J. (1983). Developmental systems: Contexts and evolution. In W. Kessen (ed.), Handbook of Child Psychology: Vol. 1. History, Theory, and Methods (4th edn, pp. 237-294). New York: Wiley.

Scholte, R. H. J., Van Lieshout, C. F. M., \& Van Aken, M. A. G. (2001). Perceived relational support in adolescence: Dimensions, configurations, and adolescent adjustment. Journal of Research in Adolescence, 11, 71-94. 
Scholte, R. H. J., Vermulst, A. A., \& De Bruyn, E. E. J. (2001). Instrument Development and Validation. Poster presented at the 6th European Association of Psychological Assessment. Aachen, Germany, September 2-5.

Segrin, C. \& Dillard, J. P. (1992). The interactional theory of depression: A meta-analysis of the research literature. Journal of Social and Clinical Psychology, 11, 43-70.

Seiffge-Krenke, I. (1997). Wie verändern sich die familiären Beziehungen im Jugendalter? Diskrepanz in der Einschätzung von Jugendlichen und ihren Eltern. Zeitschrift für Entwicklungspsychologie und Pädagogische Psychologie, 29, 133-150.

Sheeber, L., Hops, H., Alpert, A. et al. (1997). Family support and conflict: Prospective relations to adolescent depression. Journal of Abnormal Child Psychology, 25, 333-344.

Shulman, S. \& Scharf, M. (2000). Adolescent romantic behaviors and perceptions: Ageand gender-related differences, and links with family and peer relationships. Journal of Research on Adolescence, 10, 99-118.

Slavin, L. A. \& Rainer, K. (1990). Gender differences in emotional support and depressive symptoms among adolescents: A prospective analysis. American Journal of Community Psychology, 18, 407-421.

Stice, E. \& Barrera, M. (1995). A longitudinal examination of the reciprocal relations between perceived parenting and adolescents' substance use and externalizing behaviors. Developmental Psychology, 31, 322-334.

Stice, E., Barrera, M., \& Chassin, L. (1998). Prospective differential prediction of adolescent alcohol use and problem use: Examining mechanisms of effect. Journal of Abnormal Psychology, 107, 616-628.

Stice, E., Ragan, J., \& Randall, P. (2004). Prospective relations between social support and depression: Differential direction of effects for parent and peer support? Journal of Abnormal Psychology, 113, 155-159.

Vazsonyi, A. T. (2004). Parent-adolescent relations and problem behaviors: Hungary, the Netherlands, Switzerland, and the United States. Marriage and Family Review, 35, 161-187.

Wilkinson, R. B. (2004). The role of parental and peer attachment in the psychological health and self-esteem of adolescents. Journal of Youth and Adolescence, 33, 479-493.

Wills, T. A. \& Cleary, S. D. (1996). How are social support effects mediated? A test with parental support and adolescent substance use. Journal of Personality and Social Psychology, 71, 937-952.

Wills, T. A. \& Resko, J. A. (2004). Social support and behavior toward others: some paradoxes and some directions. In A. G. Miller (ed.) The Social Psychology of Good and Evil (pp. 416-443). New York: Guilford.

Windle, M. (1992). Temperament and social support in adolescence: Interrelations with depressive symptoms and delinquent behaviors. Journal of Youth and Adolescence, 21, $1-21$.

Yang, Y. \& Yeh, K. (2006). Differentiating the effects of enacted parental support on adolescent adjustment in Taiwan: Moderating role of relationship intimacy. Asian Journal of Social Psychology, 9, 161-166.

Young, J. F., Berenson, K., Cohen, P., \& Garcia, J. (2005). The role of parent and peer support in predicting adolescent depression: A longitudinal community study. Journal of Research on Adolescence, 15, 407-423.

Zimmerman, M. A., Steinman, K. J \& Rowe, K. J. (1998). Violence among urban African American adolescents: The protective effects of parental support. In X. B. Arriaga \& S. Oskamp (eds), Addressing Community Problems: Psychological Research and Interventions (pp. 78-103). Thousand Oaks: Sage Publications.

Zimmerman, M. A., Ramirez-Valles, J., Zapert, K. M., \& Maton, K. I. (2000). A longitudinal study of stress-buffering effects for urban African-American male adolescent problem behaviors and mental health. Journal of Community Psychology, 28, 17-33. 